\title{
"VOLCANIC ASH AGGREGATION ENHANCED BY SEAWATER INTERACTION: THE CASE OF THE SECCHE DI LAZZARO PHREATOMAGMATIC DEPOSIT [STROMBOLI],
}

\author{
Daniele Morgavi $^{*}{ }^{1}$, Luca Valentini ${ }^{2}$, Massimiliano Porreca ${ }^{1}$, Azzurra Zucchini ${ }^{1}$, \\ Alessandro Di Michele ${ }^{1}$, Miriam lelpo ${ }^{1}$, Antonio Costa ${ }^{3}$, Stefano Rossi ${ }^{1}$, Patrizia Landi ${ }^{4}$, \\ Diego Perugini ${ }^{1}$ \\ (1) Department of Physics and Geology, University of Perugia, Perugia, Italy \\ (2) Department of Geosciences, University of Padova, Padova, Italy \\ (3) Istituto Nazionale di Geofisica e Vulcanologia - Sezione di Bologna, Bologna, Italy \\ (4) Istituto Nazionale di Geofisica e Vulcanologia - Sezione di Pisa, Pisa, Italy
}

Article history

Receveid July 30, 2018; accepted February 20, 2019.

Subject classification:

Accretionary Lapilli; Stromboli; X-ray microtomography; 3D; Salt.

\begin{abstract}
The Secche di Lazzaro formation (ca. 6.2-7 kys BP) is a phreatomagmatic deposit situated in the southwestern part of the island of Stromboli (Aeolian Archipelago, Italy). The volcanic sequence is comprised of three main units. In the lower unit accretionary lapilli are particularly abundant and are characterized by strong cementation between the particles and an uncommon resistance to breakage. To understand the processes behind the formation of the Secche di Lazzaro (SdL) accretionary lapilli a multi-analytical approach was used on the lapilli Aggregate Tuff (AT), and on single Accretionary Lapilli (AL). We carried out granulometric analysis, Field Emission - Scanning Electron Microscopy (FE-SEM), Electron Microprobe Analysis (EMPA), X-ray powder diffraction (XRPD) and 3D imaging by X-ray micro-tomography $(\mathrm{X}-\mathrm{mCT})$. The granulometric data show that most particles in the AT have a diameter equal to $\Phi-1$ corresponding to $2 \mathrm{~mm}$. The EMPA, FE-SEM and XRPD analyses reveal the presence of different mineral phases, mainly plagioclase, K-feldspar, halite, and clinopyroxene, together with volcanic glass. From the X-mCT analysis, we constrained the particle distribution and estimated the porosity of AL. The results of the FE-SEM images provided the chemical distribution within individual lapilli allowing the identification of rim and core zoning as well as the presence of halite located both on the border of single lapilli and on the juncture between different lapilli. Moreover, halite occurs among different aggregates in single AL, thus acting as a binding agent, as well as within rim pores. The results of this work shed new light into the formation of accretionary lapilli in phreatomagmatic eruption at volcanic island involving marine water.
\end{abstract}

\section{INTRODUCTION}

Highly energetic volcanic eruptions disperse into the atmosphere enormous amounts of gas and volcanic fragments [e.g. Schmid, 1981; Costa et al., 2010]. Volcanic fragments are constituted by ash $(<2 \mathrm{~mm})$, lapilli $(2-$ $64 \mathrm{~mm}$ ) and bomb or blocks (>64mm) [Fisher, 1961; Walker, 1973; Schmid, 1981]. Ash is composed of particles of glass, crystal and lithic of cognate, accessory or accidental origin [Fischer and Schmincke, 1984]. Gener- ally but not exclusively, the percentage of ash of the total erupted mass could vary from 1 to $5 \mathrm{wt} \%$ in explosive basaltic eruption and $>50 \mathrm{wt} \%$ for silicic eruptions [e.g. Sparks et al., 1997; Rose and Durant, 2009; Costa et al., 2010; Brown et al., 2012].

The generation of ash is strongly related to the style of eruption [Walker, 1981]. Once fragmentation has started, volcanic ash is dispersed into the surrounding environment by eruption columns and pyroclastic density currents [Carey and Sigurdsson, 1982; Hildreth and 
Drake, 1992; Durant and Rose, 2009; Brown et al., 2012].

Direct observations [Carey and Sigurdsson, 1982; Sorem, 1982; Lane et al., 1993] have shown that most of the fine ash particles fall from volcanic plumes as aggregates that have larger sizes, lower densities, and higher terminal fall velocities than individual constituent particles. Aggregates form in turbulent ash clouds when particles collide with each other and the binding forces exceed the grain dispersive forces [e.g. Costa et al., 2010]. The occurrence of enough water at specific temperatures in the cloud can promote ash aggregation and the formation of accretionary lapilli. The term accretionary lapilli has been used to describe several lithologies over the past decades such as: unstructured aggregates [e.g., Hayakawa, 1990; Rosi, 1992; Sisson, 1995; Watanabe et al., 1999; Trusdell et al., 2005], multiple concentriclaminated aggregates [e.g., Cole and Scarpati, 1993; Junqueira-Brod et al., 2005; Edgar et al., 2007], aggregates with a single fine-grained coating around a massive ash core [Branney, 1991] and ash-coated lithic clasts [Bednarz and Schmincke, 1990; Palladino et al., 2001]. Schumacher and Schmincke [1991] and [1995] distinguish two different types of lapilli, based upon their internal structure: rim-type and core-type. The rim-type has a coarse-grained core surrounded by a fine grained rim and the core-type has a coarse grain core and no fine rim. Brown et al. [2012] introduced a new way of classifying aggregates, dividing the accretionary lapilli in two macro categories: particle clusters $(P C)$ and accretionay pellets $(A P) . P C$ are sub-divided according to their internal structure in ash cluster (PC1) and coated particles (PC2); both are fragile and poorly preserved in the deposit and generated during ash fall. APs are classified into three sub-categories: poorly-structured pellets (AP1), accretionary pellets (AP2) and liquid pellets (AP3); the first forms during ash fall, the second during emplacement of pyroclastic density currents (PDC) and the latter, poorly preserved in geological record, as a result of drops of water containing ash particles. Understanding the mechanisms behind the aggregate formation is of primary importance because it helps to better constrain the models for tephra dispersal. The scientific community had spent great deal of effort in trying to understand the origin of accretionary lapilli by the application of several experimental methods. In particular, Gilbert and Lane [1994] developed a recirculating wind tunnel to generate aggregates; they showed that growth is controlled by collision of liquid-coated particles due to differences in fall velocities and binding as a result of sur- face tension forces and secondary mineral growth. Schumacher and Schmincke [1995] performed two series of experiments: 1) pan agglomeration of volcanic ash and 2) electrostatic deposition of ash on a metal plate. The results of both experiments were used to study capillary binding forces in moist particles and grain size selection and deposition due to electrostatic forces. Recently Van Eaton et al. [2012], Del Bello et al. [2015], Mueller et al. [2016] and Mueller et al.,[2017; 2018] have further extended the knowledge on the mechanisms of aggregation by water bounds between particles. Van Eaton et al. [2012] used a vibratory pan to show the first trials of ice aggregation below freezing at room temperature and the influence of water content (liquid and ice) on aggregation coefficient. Del Bello et al. [2015] present the first attempt to parameterize the joint roles of aggregation and disaggregation on the behavior of volcanic ash particles transported within gaseous suspension. Mueller et al. [2016] and [2017] successfully produced aggregates in laboratory using fluidization techniques, but only when particles were coated with volumetrically relevant $\mathrm{NaCl}$ ( $2000 \mathrm{mg} \mathrm{Kg}^{-1}$ ) well-structured aggregates were recovered. These recent studies show that the involvement of water enriched in $\mathrm{NaCl}$ could enhance the formation of aggregate in natural environments. Here, we combine several techniques such as granulometric analysis, electron microprobe, X-ray powder diffraction, Field Emission - Scanning Electron Microscopy, and Xray microtomography to study the textures and chemistry of selected accretionary lapilli/pellets formed during a Holocene phreatomagmatic eruption of Stromboli (Southern Italy). The eruption produced pyroclastic sequence characterized by basal stratified, accretionary lapilli-rich deposits, which have been interpreted, in the past, as pyroclastic fallout [Bertagnini and Landi, 1996], but redefined by Giordano et al. [2008] and Lucchi et al. [2018] as emplaced by dilute phreatomagmatic PDCs.

The results of this work sheds a new light into the formation of accretionary lapilli in phreatomagmatic eruption involving marine water.

\section{GEOLOGICAL SETTINGS}

\subsection{STROMBOLI VOLCANO}

Stromboli is the north-easternmost volcanic island of the Aeolian Island Arc and together with Volcano, is one of the two presently active volcanoes of the arc. The island is elongated in the direction NE-SW (Figure 1), 


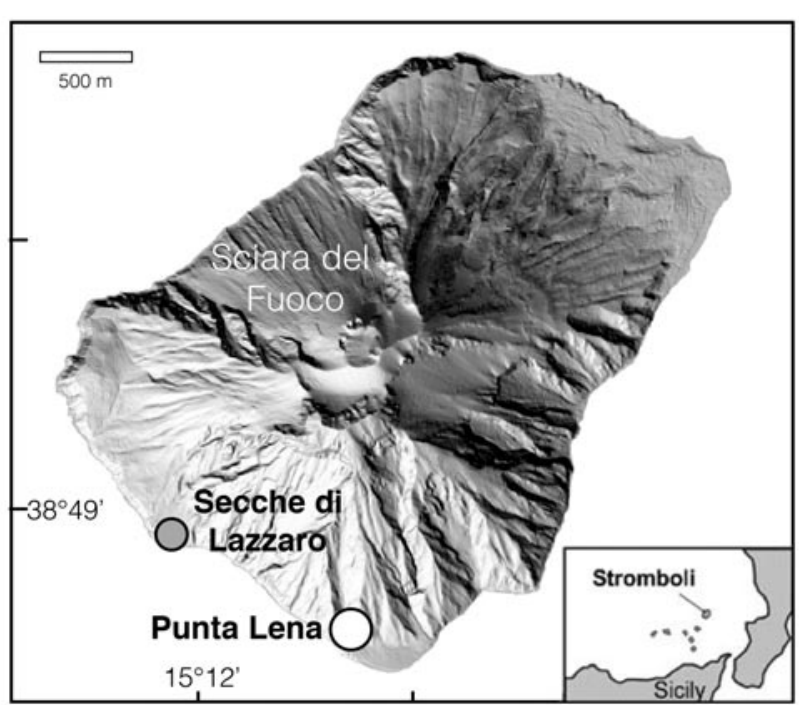

FIGURE 1. Digital elevation model (DEM) of Stromboli and location of the Secche di Lazzaro (SdL) pyroclastic sequence. The grey dot indicates the type locality (SdL), the white dot indicates the outcrop studied in this work (Lena). Map is modified from Porreca et al. [2006], Giordano et al. [2008].

parallel to the tectonic structures that are recognized in the eastern sector of the Aeolian archipelago, and towards the small island of Strombolicchio, an islet neck placed about $2 \mathrm{~km}$ from the main island [Rosi, 1980]. The volcano has an elevation of $924 \mathrm{~m}$ a.s.l and a surface area of $12.6 \mathrm{~km}^{2}$. This complex forms a strato-cone rising from a depth of $2000 \mathrm{~m}$ from the Tyrrhenian Sea [Segre, 1968]. Stromboli is characterized by alternating stages of building (eruptive phases) and destruction (from slow slope erosion, to rapid sector collapse). The subaerial part of the volcano was formed in the last 100 ky during six main periods of activity, called Paleostromboli I, II, III, Vancori, Neostromboli and Recent periods, during which rocks with varying composition from calc-alkaline (CA), high K calc-alkaline (HKCA) to shoshonitic (SHO), were emplaced [Hornig-Kjarsgaard et al., 1993; De Astis et al., 2006; Francalanci et al., 2013]. Each period includes growth and quiescence phases, separated by major unconformities related to a reduction of the eruptive activity. The construction phases alternated with important sector collapses, generally linked to major eruptions [Calvari et al., 2005; Tommasi et al., 2005], which enabled access of sea water to the volcanic conduit triggering phreatomagmatic eruptions [Bertagnini and Landi, 1996; Giordano et al., 2008]. Sector collapses are also associated with landslides and tsunami generation [Tinti et al., 2004], producing several amphitheatre depressions, such as the
Sciara del Fuoco (Figure 1). The Sciara del Fuoco scar represents the main unstable flank of the volcano where all the recent lava flows have been confined. The volcanic activity in the last 1000 years [Rosi et al., 2000] has been characterized by "persistent strombolian activity", which consists of rhythmic, mild to moderate explosions related to the emission of gas and HKbasaltic to shoshonitic ash, lapilli and scoriae. Strombolian activity is occasionally interrupted by episodes of intense activity characterized by lava emissions and/or more violent explosive events (paroxysms) [Bertagnini et al., 2008 and references therein].

\subsection{OUTCROP DESCRIPTION (SECCHE DI LAZZARO DEPOSIT, PUNTA LENA LOCALITY]}

The Secche di Lazzaro (SdL) sequence marks the end of the Neostromboli period at ca. 6.2-7 kys BP [Speranza et al., 2008; Francalanci et al., 2013; Lucchi et al., 2018 and references therein] and has been associated with a phreatomagmatic eruption triggered by the main collapse of the Sciara del Fuoco [Bertagnini and Landi, 1996; Porreca et al., 2006 and Giordano et al., 2008]. The deposits related with this eruption crop out at various locations in the south-western portion of the island and are the best example of accretionary lapilli-bearing deposits of Stromboli [see Lucchi et al., 2018 for a detailed description of the ash-rich pyroclastic deposits]. The type section is located close to Ginostra village, and gives the name to this phreatomagmatic sequence, i.e. Secche di Lazzaro. Here the whole sequence is composed by three depositional units [UA, UB and UC of Giordano et al., 2008]. UA constitutes the basal portion of the succession and comprises several parallel- to cross-stratified ash beds, with abundant accretionary lapilli. UB is matrix-supported, generally massive, from chaotic to diffusely stratified deposit with rare accretionary and armored lapilli. The upper UC caps the succession with thick post-eruptive lahars composed by lithic rich, massive and chaotic, matrixsupported deposits, without accretionary lapilli. Other outcrops of the same sequence are located at Punta Lena (in the south coast of the island, Figure 1) at ca. $30 \mathrm{~m}$ a.s.l., where the samples of this work were collected. Here, the sequence is characterized by stratified, accretionary lapilli-rich, lapilli tuff deposits (Figure 2A). The outcrop rests on Neostromboli lava, and is confined to a narrow, U-shaped paleo-valley (Figure 2A) and nearby scattered outcrops. The authors recognize here two units. The lower unit [UA of Giordano et 

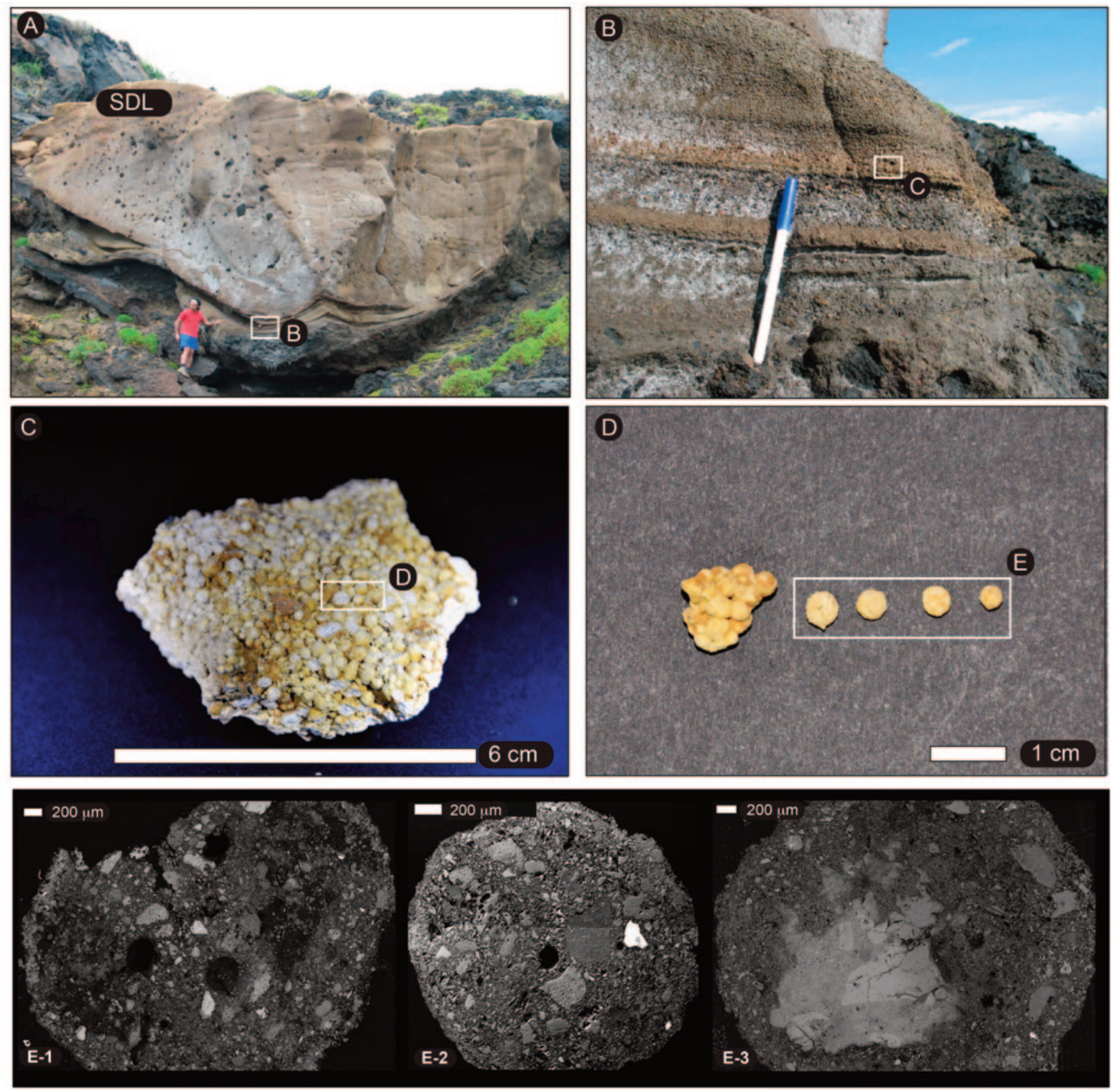

FIGURE 2. A) SdL pyroclastic sequence at Punta Lena locality; B) the lapilli-bearing layers at the base of the SdL sequence; C) Hand sample showing the accretionary lapilli tuff (AT); D) small section of (AT) where, as an example, four accretionary lapilli (AL) were separated; E-1, E-2, E-3) different BSE images of sectioned in half (AL) showing the internal structure of the aggregate. The samples of this study are collected in these layers [modified after Giordano et al., 2008].

al., 2008] of the sequence is composed of 10 beds, characterized by alternating thin, faintly laminated, ash layers and accretionary and armoured lapilli-rich, 2-15 cm-thick layers (Figure 2B). The samples analysed in this study have been collected from these accretionary lapilli layers. The upper unit [UB of Giordano et al., 2008] of this stratigraphic sequence is characterized by matrix-supported beds with cross-stratification, containing accretionary lapilli and armoured lapilli up to $2 \mathrm{~cm}$ in diameter dispersed into the deposit (2-5\% of the total deposit).
Regarding the interpretation of the emplacement mechanism for the lower unit, different opinions are discussed in literature, even if the most recent works are concordant with an emplacement by dilute PDCs produced by magma-water interaction. Bertagnini and Landi [1996] interpreted the Secche di Lazzaro deposits as a fairly plane-parallel fallout sequence. According to Giordano et al. [2008] and Lucchi et al. [2018], the stratigraphy indicates an origin from repeated dilute PDCs or PDC pulses, which produce a repetition of basal chaotic ash and accretionary lapilli layers. 


\section{MATERIALS AND METHODS}

\subsection{SAMPLES}

The lapilli tuffs collected at Punta Lena, are essentially constituted by tuffs bearing accretionary lapilli of different sizes held together by a grey-yellow matrix of volcanic ash (see Figure 2C hand specimen sample). The aggregates are not dispersed in the ash matrix but form clast supported accretionary-lapilli deposits. A representative number of samples, several accretionary lapilli tuffs from the same layer were collected to perform: granulometry, chemical/mineralogical determination and $\mathrm{X}$-ray computed microtomography analysis. As we mentioned above, in this work, AT stands for the accretionary lapilli-bearing layer or accretionary lapilli tuff and AL for the single accretionary lapilli.

\subsection{SAMPLE PREPARATION AND GRAIN-SIZE ANALY- SIS}

Samples preparation and grain size analysis were performed at the Department of Physics and Geology, University of Perugia (Italy). Each AL was separated by hand from the ash matrix avoiding breakage (Figure 2D). The size distribution analyses of AL were performed by hand shaking using a sieve set at half $-\Phi$ steps for the fractions between $\Phi=0$ and $\Phi=1.5$ and at 0.2-0.3 $\Phi$ steps for the coarser fractions (between 0 and -2). The parameter $\Phi$ corresponds to - $\log 2 \mathrm{~d}$ where " $\mathrm{d}$ " is the diameter of the grain in $\mathrm{mm}$. Each granulometric fraction was weighed using a precision balance $\left( \pm 10^{-4} \mathrm{~g}\right)$, and the values converted into weight $\%$ of the particle-size class according to Walker [1971]. One AL was selected for each granulometric class for X-ray computed microtomography analyses.

A representative section of the AT of $22 \mathrm{~mm}$ and a selections of AL were embedded in epoxy resin creating two cylindrical sample of 1" (25.4 mm) in diameter each; all samples were then polished for chemical analysis.

\subsection{ELECTRON MICROPROBE}

Concentrations of major elements on glasses and crystals were measured through a Cameca SX100 electron microprobe (Earth and Environment, LMU-Munich). The operating conditions were $15 \mathrm{kV}$ acceleration voltage and $20 \mathrm{nA}$ beam current. A defocused $10-\mu \mathrm{m}$ beam was used for all elements in order to avoid alkali loss. Synthetic wollastonite (Ca, Si), periclase (Mg), hematite (Fe), corun$\operatorname{dum} \mathrm{AL}$, natural orthoclase $(\mathrm{K})$, and albite $(\mathrm{Na})$ were used as standards, and matrix correction was performed by
PAP procedure (Pouchou and Pichoir, 1984). Standard deviations were lower than 2.5\% for all analysed elements. High-magnification backscattered electron (BSE) images of polished sections of AL were also acquired.

3.4 X-ray powder diffraction analysis

$\mathrm{X}$-ray powder diffraction (XRPD) analysis was performed at the Department of Physics and Geology, University of Perugia (Italy) to obtain quantitative mineralogical composition of the studied samples. In particular, two XRPD analyses were performed, (i) on the AT and (ii) on the isolated AL.

The data collection was carried out at room temperature by means of a Philips PW-1830 diffractometer in Brag-Brentano $\theta-2 \theta$ geometry, with $\mathrm{Cu}-\mathrm{K} \alpha$ incident radiation $(\lambda=1.5406 \AA$ ) and a graphite monochromator. Data were collected in the $5^{\circ}$ to $80^{\circ} 2 \theta$ range, $0.02^{\circ}$ step size, 20 s step time. The $\mathrm{Cu} \mathrm{X}$-ray tube was operated at $40 \mathrm{kV}$ voltage and $30 \mathrm{~mA}$ current intensity. The amorphous content in the analysed samples was checked by means of the external standard method following the Hill and Howard [1987] approach. The external standard was a 99.5\% metal based powdered crystalline Silicon (325 mesh) from Alfa Aesar. A constant Si amount of $10 \mathrm{wt} \%$ was added to the powders prepared for the XRPD analysis.

The collected powder patterns were refined using the Rietveld method [Rietveld, 1969] by means of GSAS General Structure Analysis System [Larson and Von Dreele, 2004] to obtain the quantitative mineralogical composition of the analysed samples. Background was fitted with 30-term Shifted Chebyshev polynomial function. The starting crystal structure for each phase was taken from literature as listed in Table 1. Scattering factors for neutral atoms were used. Profile fitting was performed by means of a pseudo-Voigt peak shape function [Thompson et al., 1987] with one Gaussian (GW) and one Lorenzian (LX) coefficient [Larson and Von Dreele, 2004]. Together with background and profile functions, the refined parameters were: cell parameters, isotropic displacement parameters and scale factors. When needed, the March-Dollase algorithm [Dollase, 1986] was used for preferred orientation correction.

\subsection{FIELD EMISSION SCANNING ELECTRON MI- CROSCOPY}

A field-emission (FE) - scanning electron microscope (SEM) (LEO 1525), available at the Department of Physics and Geology of the University of Perugia (Italy), 


\begin{tabular}{cc} 
Phase & References \\
Sanidine & Kimata et al. [1989] \\
Anorthite & Angel et al. [1990] \\
Glauconite & Drits et al. [2010] \\
Augite & Clark et al. [1969] \\
Ca-phillipsite & Rinaldi et al. [1974] \\
Halite & Walker et al. [2004] \\
Muscovite & Gueven [1977] \\
\hline
\end{tabular}

TABLE 1. Mineral phases used for Rietveld refinements. Mineral names and reference structure models are listed.

was used to collect high-resolution SEM images from the analysed samples after carbon coating. BSE images were collected by means of a ZEISS 1-Channel-AsB Detector. Elemental composition analysis and chemical mapping were performed by means of a Bruker Quantax EDS.
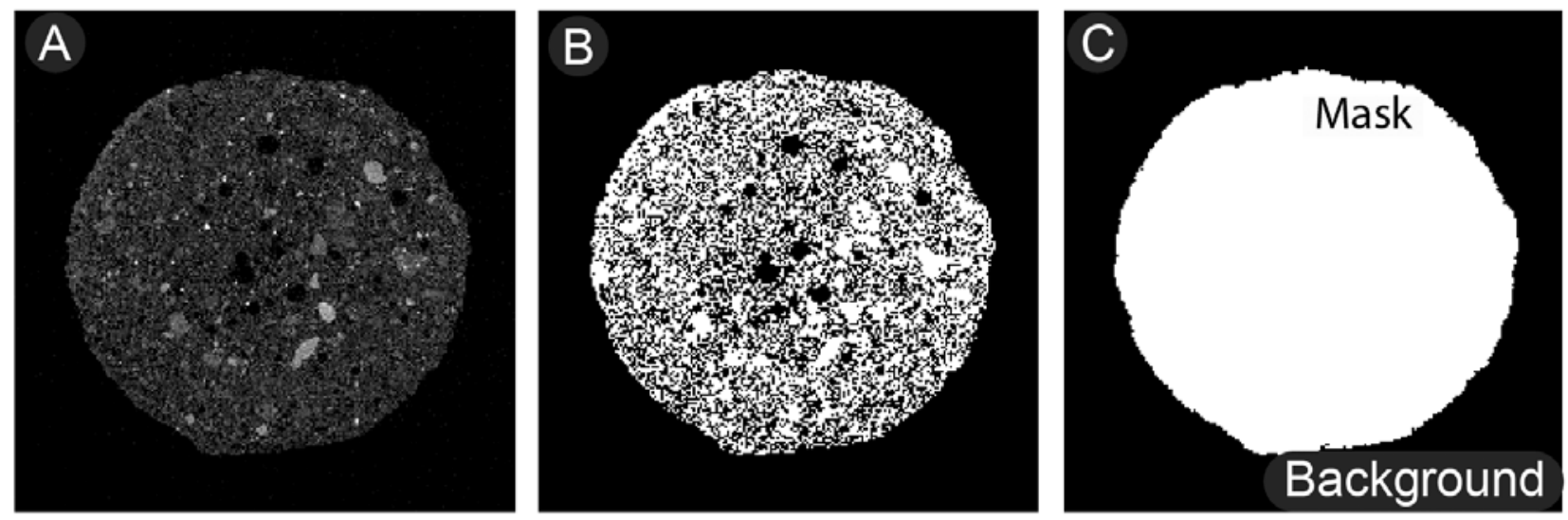

FIGURE 3. An example of a conventional X-ray microCT image of a single accretionary lapillus. (A) Reconstructed 2D axial slice and (B) after a binary thresholding, attempting to segment the lapilli Image processing steps for pore volume calculation (C) mask for background removal.

\subsection{X-RAY COMPUTED MICROTOMOGRAPHY AND IMAGE ANALYSIS}

Although X-ray computed microtomography (X-CT) is becoming increasingly valuable in the geosciences [Ketcham and Carlson, 2001; Mees et al., 2003; Ketcham, 2005; Carlson, 2006; Gualda et al., 2010; Polacci et al., 2010; Voltolini et al., 2011; Baker et al., 2012a,b; Iglauer et al., 2012; Blunt et al., 2013; Fusseis et al., 2014; Wiesmaier et al., 2015; Valentini et al.,
2015; Arzilli et al., 2016; Morgavi et al., 2016; ParedesMariño et al., 2017], so far the application of this method to the study of accretionary lapilli is limited to a single study [Van Eaton et., 2012]. In this study, XCT scans were performed using a Skyscan 1172 (Bruker, Billerica, US) at the Geosciences Department (University of Padova, Italy) equipped with a W X-ray source. Radiographs of each AL were acquired with $74 \mathrm{kV}$ voltage and $113 \mathrm{~mA}$ beam current, with a rotation step and exposure of $0.25^{\circ}$ to $0.30^{\circ}$ and 1050 to $1375 \mathrm{~ms}$, depending on the size of the specimen. For AT samples, the X-ray source was set to $100 \mathrm{kV}$ and $100 \mathrm{~mA}$ and the radiographs were acquired with $0.35^{\circ}$ rotation step and $3500 \mathrm{~ms}$ exposure time.

Vertically stacked cross-sectional slices were reconstructed using the Feldkamp algorithm [Feldkamp et al., 1984]. The pixel size of the reconstructed images ranges from 2.7 to $4.0 \mu \mathrm{m}$, as a function of the physical size of the AL. The pixel size of the AT is $13.6 \mu \mathrm{m}$. The reconstructed images were processed with the aim of calculating the pore volume within the AL. The first step of the image processing consisted of a conversion from grey scale to binary images. This was achieved by 


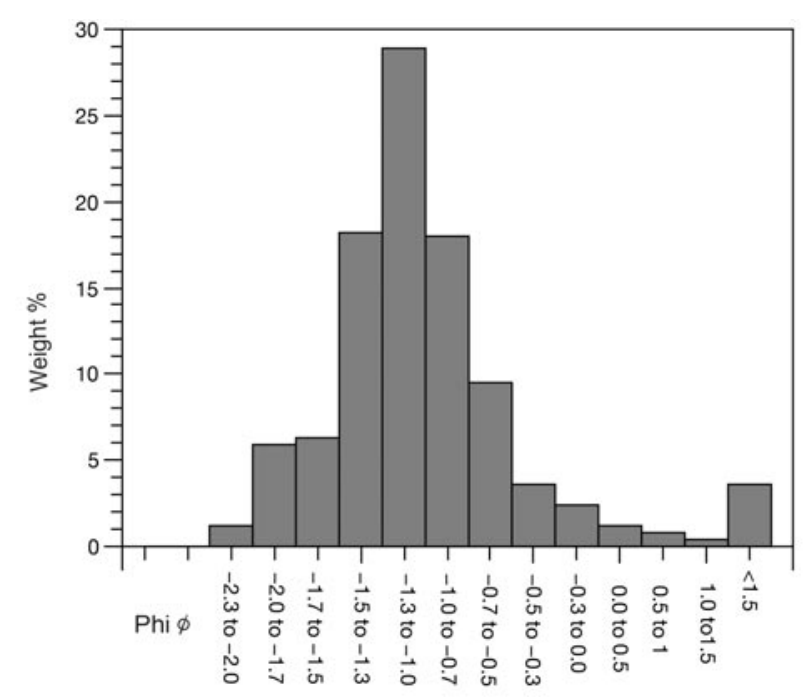

FIGURE 4. Grain-size distribution of the accretionary lapilli inside the deposit. An anomalous thickening of the finer part (not following a Gaussian distribution) is representing the fine ash between lapilli.

volumes for all samples has been obtained with the commercial software VGStudio MAX 2.0 selecting a volume rendering procedure. The first step of the volume rendering process consists of the extraction of a Volume Of Interest (VOI). After the extraction of the VOI, the volume is usually pre-processed with filters to facilitate the processing of images, i.e. reducing noise and potential artefacts, to enhance the edges of the objects and to distinguish better the different phases.

\section{RESULTS}

\subsection{OPTICAL AND GRANULOMETRIC ANALYSIS}

The majority of the AL in the AT have a sub-spherical shape (Figure 2C-D). Only few lapilli have prolate (elongated) ellipsoid shape, and few large aggregates, in the range from 3 and $4 \mathrm{~mm}$, show oblate (flattened) ellipsoid shape (Figure 2C). The grain size distribution of the AL inside the AT is shown in the histogram weight $\%$ vs grain diameter in $\Phi$-units (Figure 4). Overall the data show a good sorting for the AL and the grain size distribution appears unimodal with the mode (29 wt\%) in the range of $-1.3 /-1 \Phi$ corresponding to AL size of $\sim 2 \mathrm{~mm}$. Ash particles instead accumulate in the size below $1.5 \Phi$. From the cumulative curve of the granulometric data, following the methodology of Inman [1952], we calculate the median diameter $\operatorname{Md} \phi$ (the $\Phi$ value at which the curve crosses the $50 \mathrm{wt} \%$ level) and the deviation $s \Phi$ (half the distance in $\Phi$ between the points at which the curve crosses the 84 and $16 \mathrm{wt}$ $\%$ levels). We obtain for $\mathrm{M} d_{\Phi}$ a value equal to $-1.1 \Phi$ and for the deviation $\mathrm{s}_{\Phi}$ equal to 0.44. Plotting those results ( $\mathrm{s}_{\Phi}$ against $\mathrm{M} d_{\Phi}$ ) into the diagram of Walker [1971], considering our AL as a single particle, our data fall into the field of pyroclastic fall. Overall the lapilli tuff (Figure 2C-D) at Punta Lena is composed by 96 wt $\%$ of aggregates and $4 \mathrm{wt} \%$ of ash material.

\subsection{EPMA ANALYSIS}

Figure 2E shows three images representative of the texture and lithological characteristics of the AL. Due to the intrinsic limitation of a $2 \mathrm{D}$ approach through two-dimensional (2D) BSE images, and the possibility of analysing the textural features using a three-dimensional (3D) non-destructive technique (paragraph 4.5 X-ray microCT analysis), below we report the main textural evidence leaving the detailed description to the $\mathrm{X}$-ray computed microtomography section.

The shape of the fragments in the aggregates varies from very angular to sub-rounded (Figure 2E-1-2-3). The vesicles shapes vary from sub-angular (Figure 2E1; and Figure 3A-B) to sub-spherical (Figure 2E-2) and are generally chaotically distributed even if in some case vesicles located in the core of the aggregate (Figure 2E-2). In the same AL we discovered large clasts of different origin (mineral, lithic or glass) placed in the core (Figure 2E-3).

The AL are characterized by the presence of glass (Figure 5A), olivine (Figure 5B), clinopyroxene (Figure 5C) and plagioclase (Figure 5D); the Cpx and Plag are the most abundant phases in agreement with Petrone et al., [2009]. From the total alkali diagram [Le Bas et al., 1986] the glasses fall in the trachy-andesite compositional field. We found some small compositional differences among the glass particles giving a $\mathrm{SiO}_{2}$ range of 55-59 wt\%, in line with data from Bertagnini and Landi [1996] and Petrone et al., [2009]. The olivines in our AL (Figure 5B) show a fairly homogenous composition with forsterite (Fo) contents ranging between 62 and 65\% with a compositional range even narrower than the one showed by Petrone et al., [2009] (between 65 and 72\%). The diagram in Figure 5C shows that all the clinopyroxenes are augitic in composition also in agreement with Petrone et al., [2009]. The plagioclase plot Figure 5D shows that the crystals in our samples span from anorthite to labradorite with the majority sitting between the anortite and the bytownite area. 


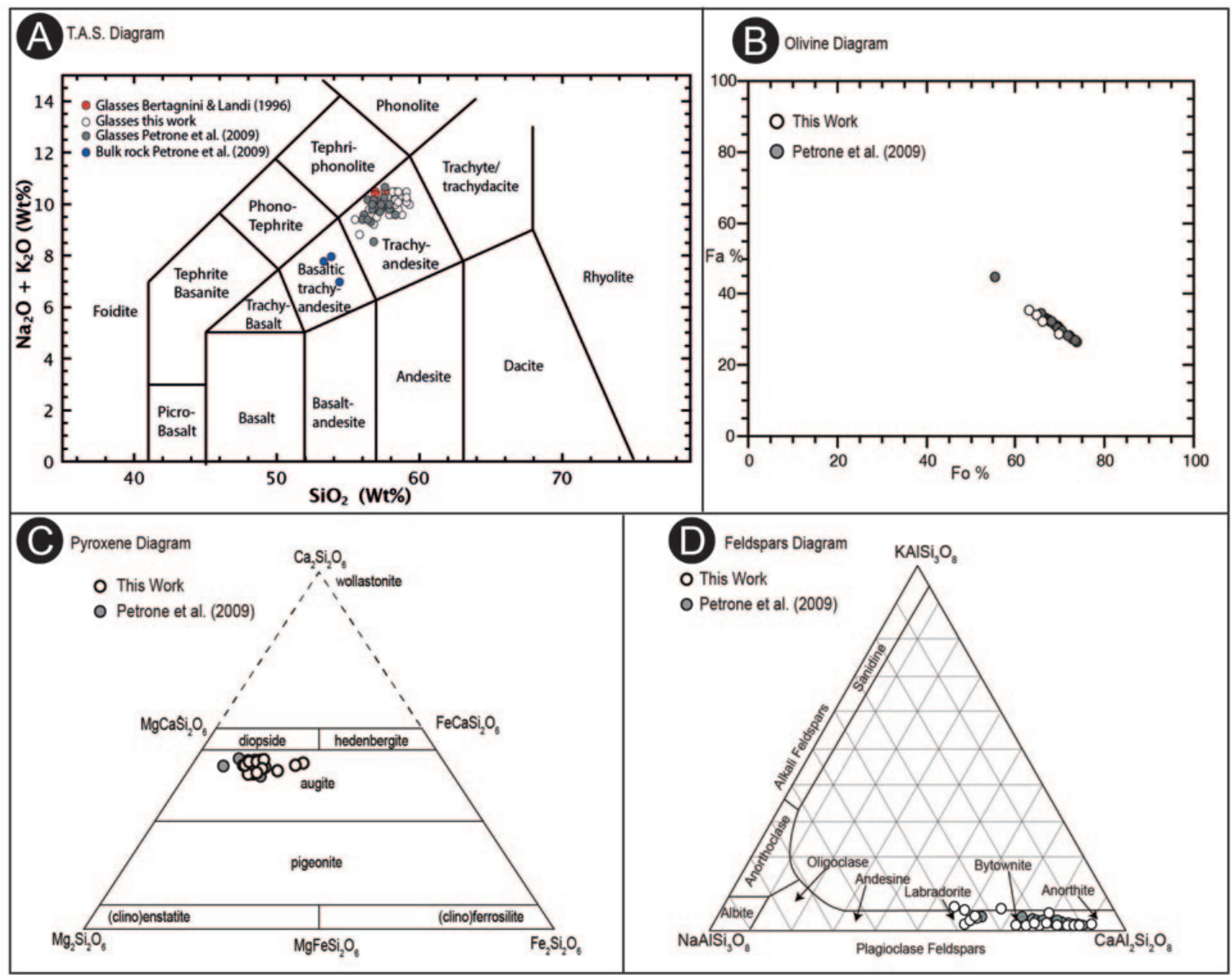

FIGURE 5. Chemical composition of glasses and minerals present in the accretionary lapilli. A) Total alkalis vs. $\mathrm{SiO}_{2}$ (TAS) classification [Le Bas et al., 1986], for the glass. Data are normalized to 100\%. B) The diagram shows the chemical composition of the olivine. C) Chemical composition of the pyroxene plotted in the Wo-En-Fs classification diagram. D) Chemical composition of the feldspar plotted in the Ab-An-Or classification diagram. Data from Bertagnini and Landi [1996] and Petrone et al. [2009] are reported as comparison.

\subsection{XRPD ANALYSIS}

Results from XRPD analysis for AT and AL are reported in Figure 6 and Table 2. The quantitative Rietveld analysis [Rietveld, 1969] allowed a detailed characterization of the presence and abundance of the mineral phases as well as the amount of amorphous material in the analysed samples. Both the AL and the AT consist of the same mineral mixture: K-feldspars (sanidine), Caplagiocalse (bytownite), pyroxenes (augite), micas (muscovite and glauconite) and zeolites (Ca-phillipsite). Moreover, halite was found on both the analysed samples. Halite content varies from approximately $4 \mathrm{wt} \%$ in AL to approximately $9 \mathrm{wt} \%$ in AT. The presence of halite in the lapilli aggregate will be discussed in detail in the following section. In Table 2 the amorphous content of the two samples is also shown as it results from the external standard method [Hill and Howard, 1987] (see par. 3.4), being 66.4(2) and 57.0(2) wto for AL and

\begin{tabular}{ccc}
\hline Phase & AT & AL \\
Sanidine & $9.62(8)$ & $9.48(9)$ \\
Anorthite & $16.07(9)$ & $14.16(9)$ \\
Halite & $8.72(5)$ & $4.29(3)$ \\
Augite & $2.23(5)$ & $2.36(5)$ \\
Ca-phillipsite & $2.7(1)$ & $1.02(9)$ \\
Muscovite & $2.69(9)$ & $1.32(8)$ \\
Glauconite & $0.98(6)$ & $0.93(7)$ \\
Amorphous & $57.0(2)$ & $66.4(2)$ \\
Rp (\%) & 5.3 & 5.1 \\
Rwp (\%) & 7.0 & 6.6 \\
Chi & 2.06 & 2.03 \\
\hline
\end{tabular}

TABLE 2. Results of the Rietveld refinements [Rietveld, 1969] of the XRPD collected profiles for AT and AL samples. The abundance of the recognizes phases, as well as of the amorphous content, is given in wt $\%$ together with standard reliability factors of the Rietveld refinements $\left(\mathrm{Rp}, \mathrm{Rw}, \mathrm{Chi}^{2}\right)$. Errors are in Brackets 

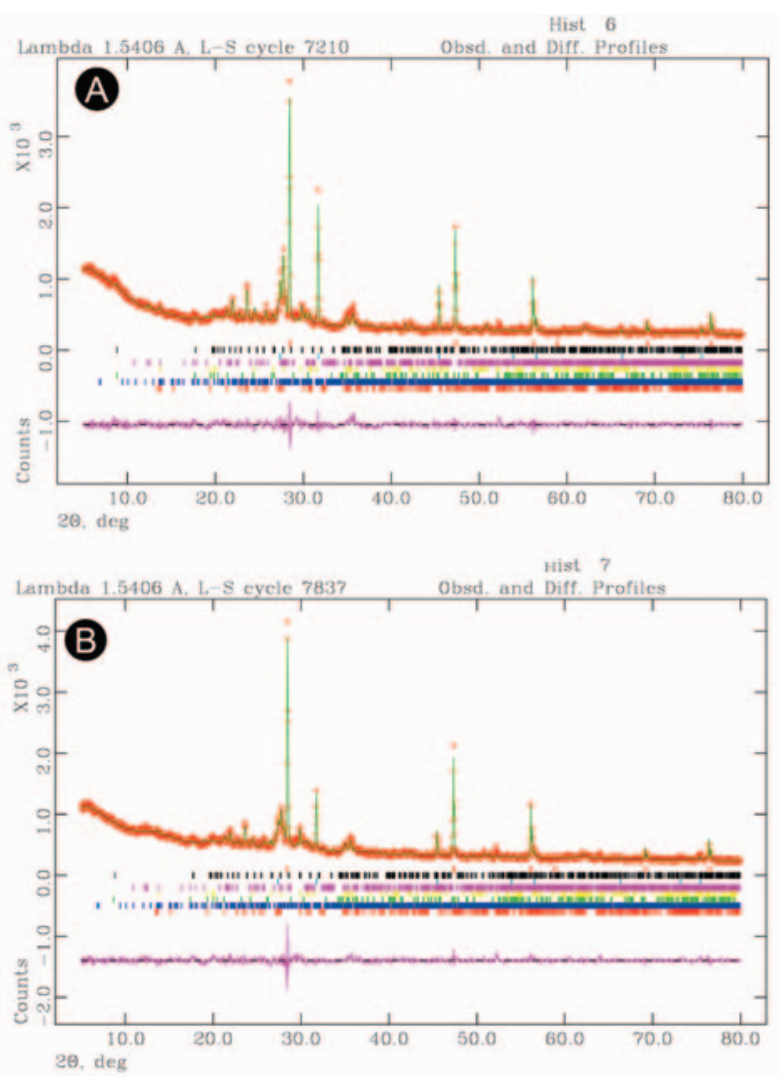

FIGURE 6. Refined XRPD profiles for (a) LA and (b) AL samples. The red crosses are the observed data and the green profile is the calculated pattern. The difference curve is shown in purple. Thick-marks below the XRPD profiles are the diffraction peaks from the reference phases. Colours are attributed to each phase as listed below, from the top to the bottom. Red: silicon; black: muscovite; cyan: halite; purple: Ca-phillipsite; yellow: augite; green: glauconite; blue: anorthite; red: sanidine.

AT, respectively. The slight decrease of the amorphous content observed in AT is likely due to the higher content of crystalline phases, especially halite, in the material binding single AL in AT with respect to the inner composition of the isolated AL.

\subsection{FE-SEM ANALYSIS}

The collected high resolution FE-SEM images coupled with the Energy Dispersive X-ray Spectroscopy (EDS) chemical analysis were used to analyse the distribution of chemical elements within the AT and AL. Schumacher and Schmincke [1995] identify three type of liquid binding: liquid droplet, liquid bridges and liquid filled pore space. In light of this we performed chemical mapping on our samples identifying distribution of halite reflecting those types of binding. Our results (Figure 7) show a ubiquitous concentration of halite at different scale from 30 to $800 \mu \mathrm{m}$, in the AL and in the AT.
We found halite spread all over the wall of voids (Figure 7 Drop), among particles (mineral and glasses) and between AL (Figure 7 Fluid Bridges and Filled Pore Space).

\subsection{X-RAY MICROCT ANALYSIS}

We performed X-ray microCT analysis (Figure 8) on the AT and on twelve AL representing each granulometric class (Figure 4) of the AT. In Figure 8 we present the most representative features of our samples. We selected four section for each features placed in a grid of four squared and named respectively A-B-C-D. The top left grid (A-B-C-D) shows several sections, cut through the AT; in square B we have single AL highlighted in green colour, from these sections it appears how the AL are heterogeneous in the deposit, being armoured and not-armoured with crystal and glass fragments in between. The top right grid (A-B-C-D) is showing several cuts through an AL in square B and D; the drop-like porosity is highlighted in red (spherical vesicles). Bottom left grid (A-B-C-D) shows a section through an armoured AL, the clast is highlighted in orange in square B. Bottom right grid (A-B-C-D) display several cuts through an AL: for this sample we have highlighted some irregular porosity commonly generated by interstitial $\mathrm{H}_{2} \mathrm{O}$ connection, square $\mathrm{B}$ and $\mathrm{C}$.

The details offered by the 3D analysis helped us to classify our samples according to Brown et al., [2012] as accretionary pellets $(A P)$. In particular, the AT in Figure 8-1 is mostly composed of poorly-structured pellets (AP1) and few AP2 with poorly marked rims (see Figure 2E-2 as another example). Using the classification of Schumacher and Schmincke [1995] instead our lapilli belong to the core type lapilli (Figure 2E and Figure 8). Our samples appear to be very similar to those described in Bonadonna et al. [2002] during vulcanian explosions at Soufriere hills volcano, Montserrat and Brown et al. [2003] for Poris PDC deposit and La Caleta PDC deposit, Tenerife.

For each of the 12 selected AL we calculate the roundness using the Roundness formula:

$$
R o=4 \frac{\alpha}{m_{j}^{2}}
$$

where $\alpha$ is the area of ellipsoid contouring the centre of the AL obtained from the $3 \mathrm{D}$ slices, and $m_{j}$ is the major axis of the ellipsoid. Our roundness results displayed in Figure 9 show three groups of particles: the largest one (4 to $3 \mathrm{~mm}$ ) having a roundness value rang- 


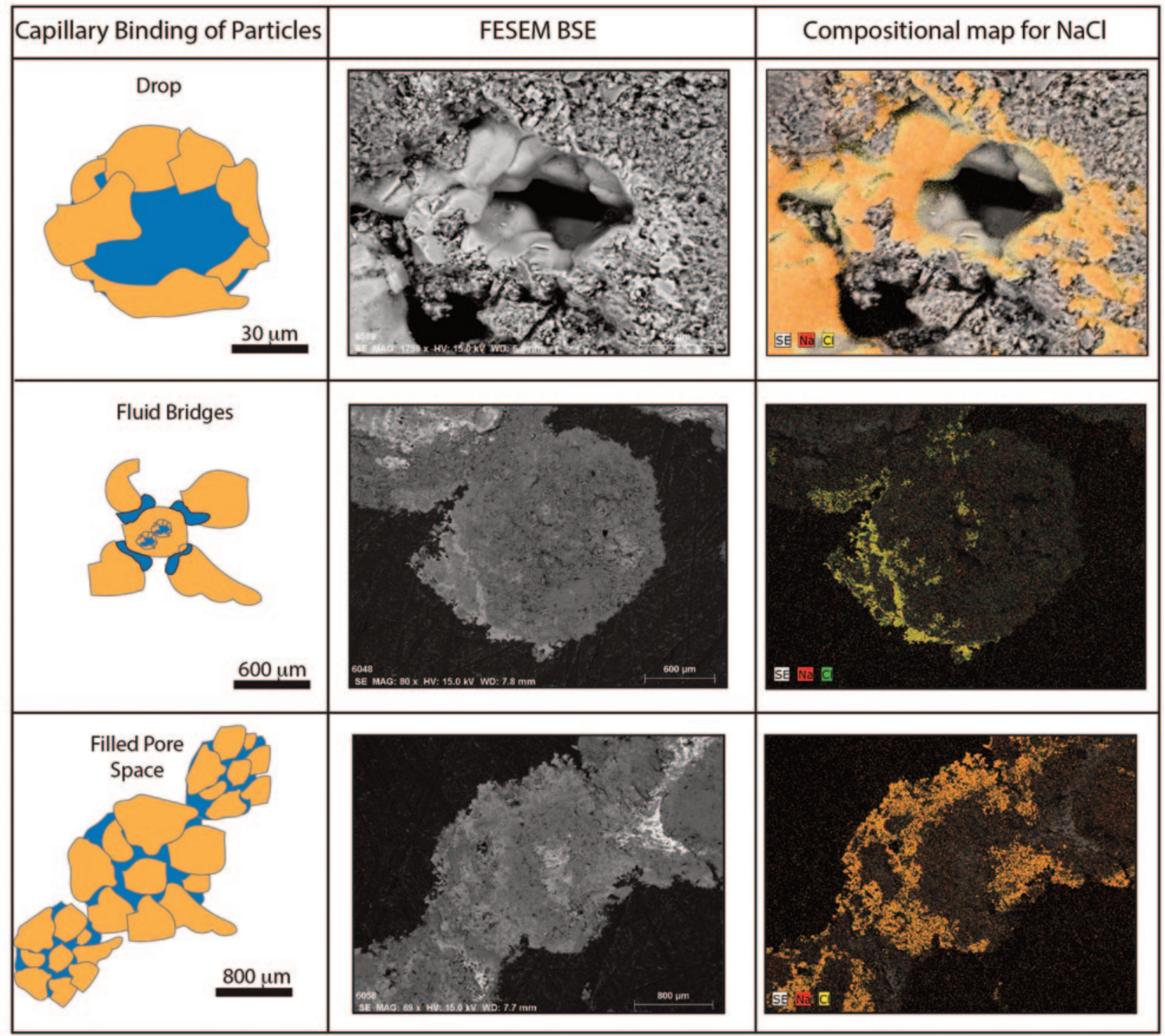

FIGURE 7. In the left part of the figure are sketched the capillary binding of particles as described by Schumacher and Schmincke [1995]: liquid droplet, liquid bridges and liquid filled pore space. In the central part of the figure FE-SEM BSE images collected on selected portions of the bulk lapilli aggregate. In the right part of the figure are represented the elemental chemical mapping related to the FE-SEM BSE. In each image the analysed elements are shown.

ing from 0.74 to 0.87 , the medium one ( 3 to $1 \mathrm{~mm}$ ) with values ranging from 0.94 to 0.98 , and the smallest one (1 to $0.4 \mathrm{~mm}$ ) having a value from 0.89 to 0.71 .

Therefore, the roundest particles in the Secche di Lazzaro AT deposit are those falling in the intermediate range from 3 to $1 \mathrm{~mm}$, which also correspond to the highest particle concentration in the AT (see Figure 4 phi range -1.7 to 0.0$)$. Moreover, we added to the roundness diagram the pore volume calculated by image analysis from the tomography data (Figure 9) from each of the twelve AL.

The pore volume in percent for AL ranges from 33\% to $40 \%$ in the size interval $4-1 \mathrm{~mm}$, and from 20 to $4 \%$ in the size interval 1-0.4 $\mathrm{mm}$.

\section{DISCUSSION}

\subsection{ASH AGGREGATES FORMATION}

The integration of the laboratory techniques allowed us to investigate in detail the composition and the 3D texture of the ash aggregates and the mechanisms related to their origin during the Secche di Lazzaro (SdL) phreatomagmatic eruption at Stromboli volcano.

The chemical analyses performed on the ash inside $\mathrm{AL}$ and AT show the presence of glass, olivine clinopyroxene, and plagioclase in agreement with previous studies [Bertagnini and Landi, 1996; Petrone et al., 2009], showing a direct correlation between the ash particles within a single AL and the main components of 


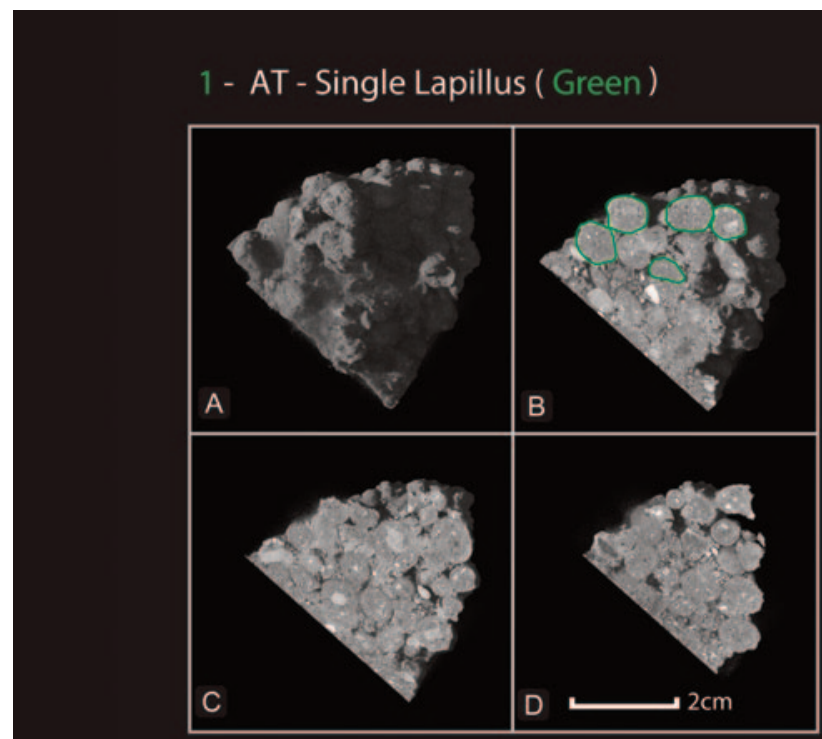

\section{2 - Drop like porosity (Red)}

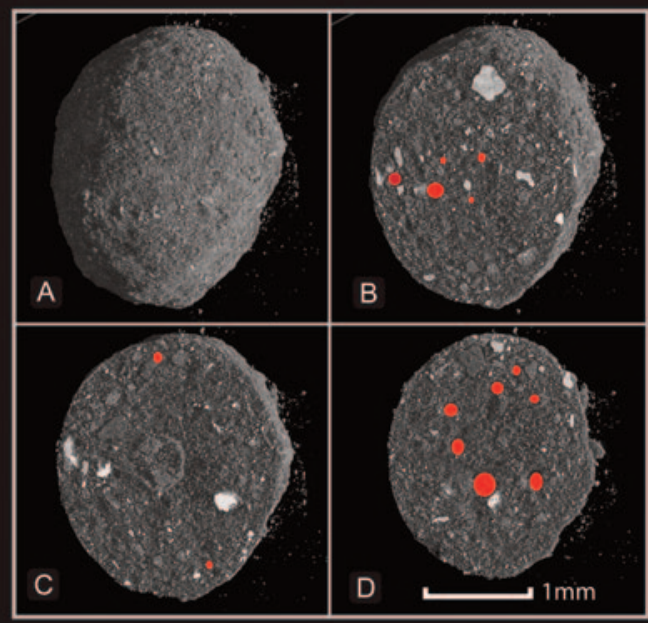

3 - Armored Lapilli (Orange)

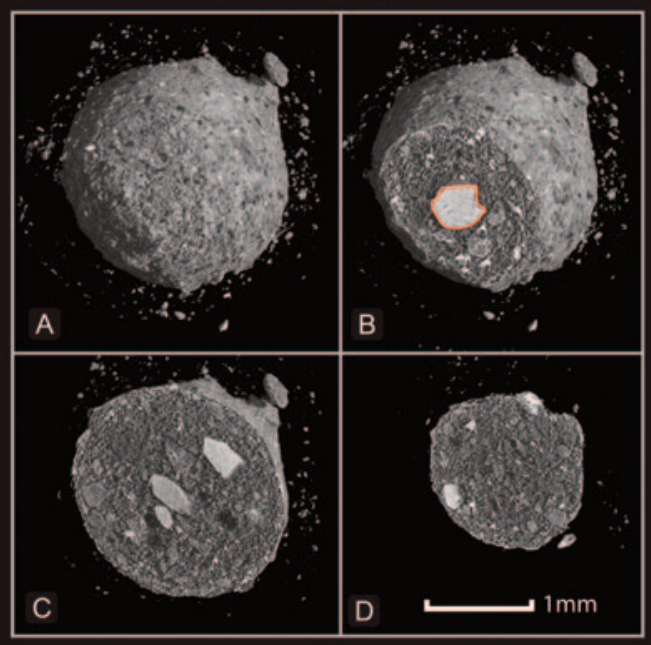

\section{4 - Interstitial $\mathrm{H}_{2} \mathrm{O}$ connection (Blue)}

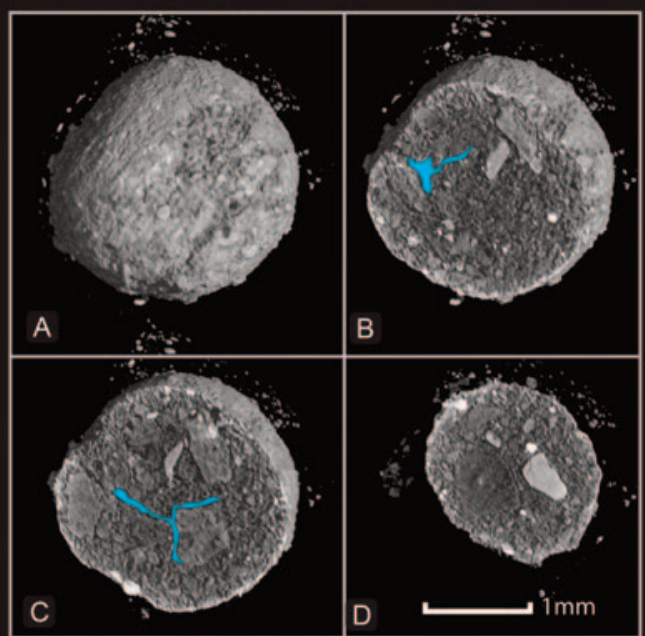

FIGURE 8. 3D reconstruction of the lapilli deposit (AT) and three representative accretionary lapilli (AL) showing different textural features. 1) it shows different 3D slice (A-B-C-D) of the accretionary tuff and in green are marked single lapilli inside the AT. 2) it shows different 3D slice (A-B-C-D) of an accretionary lapillus (AL) where in red are highlighted the drops like porosity. 3) it shows different 3D slice (A-B-C-D) of an accretionary lapillus (AL) where in orange is highlighted a particle acting as a nuclei of growth for the AL. 4) it shows different 3D slice (A-B-C-D) of an accretionary lapillus (AL) where in blue are highlighted the cavities left in the AL by the interstitial water connection.

the whole SdL deposit.

In the field, one of main feature of the AT is the high grade of cohesion, either of the single particles (glasses, lithics, and crystals) in the AL or at the scale of the whole AT. The strong cohesion suggests that they were clustered together (particles and lapilli) by an "efficient cement" associated with salted water. The presence of halite was found at different scales (30 to $800 \mu \mathrm{m}$ ) and between different components (glass, crystals, and lithics) in the AL and between AL. The mechanisms of transportation and deposition of halite is by liquid, requiring a relatively low temperature of the eruption (i.e. emplacement temperatures $\mathrm{T}<140^{\circ} \mathrm{C}$ for the UA in Porreca et al., 2006). Accumulation of halite is then the reflection of a liquid binding between particles. The binding mechanisms (Figure 7A-B-C) for aggregates as defined by Schumacher and Schmincke [1995] are liquid bridges, liquid filled pore space or liquid droplet; we found all of them in our samples together with precipitated halite. Our high concentration of halite in the binding acted as cement that increased the capacity of the AL to preserve its original shape during deposition, forming a consolidated AT. Our findings concerning the high concentration of halite are in agreement with 


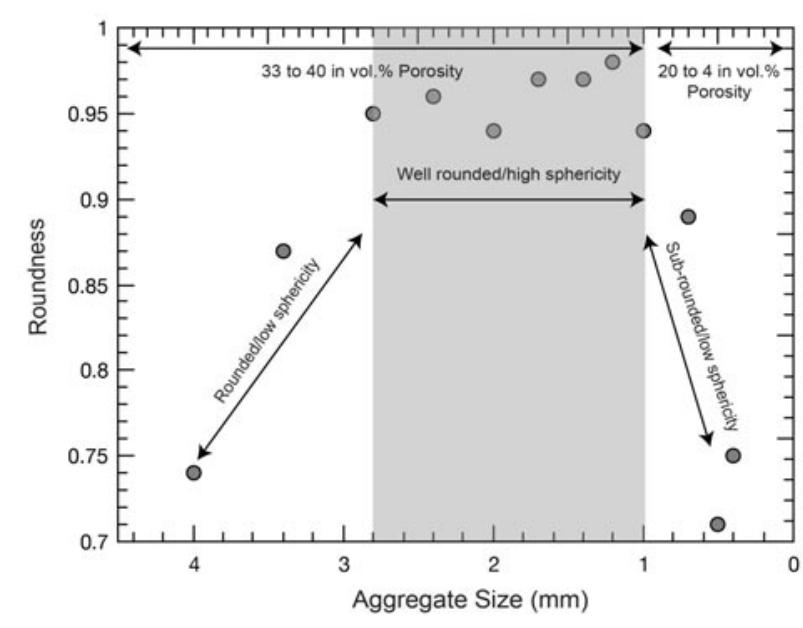

FIGURE 9. IRoundness vs. aggregates size in $\mathrm{mm}$, the grey area is the size range where we measured the highest roundness value. On the top of the diagram is also reported the value of the porosity obtained from the $3 \mathrm{D}$ tomography data.

the data from experimental results, where the presence of precipitated salts deriving from liquid films coating particles enhanced aggregation and resistivity to breakage [Muller et al., 2016].

Bertagnini and Landi [1996], Giordano et al. [2008], and Petrone et al. [2009] state that during the magma ascent, an important amount of water, due to the collapse of the Sciara del Fuoco, triggered the phreatomagmatic eruption of SdL. Our results further confirm this hypothesis, showing also that the water which interacted with the magma was sea water. Salt in the water strongly influenced ash interaction during the eruption promoting an efficient aggregation while ash was erupted. Lucchi et al. [2018] have recently discussed the possibility that the hydrothermal system may have provided the required amount of external water and fluids for an efficient magma-water interaction during the SdL eruption. Differently by this interpretation, important amounts of halite found in closed pores within the accretionary lapilli investigated in this study represent unequivocal evidence of the marine origin of the water that trigged the phreatomagmatic eruption. We can not exclude that some amount of halite, especially the one found in the external part of the AL, could be present as a consequence of littoral blasts [see Dufek et al., 2007] occurring during the arrival of the pyroclastic flow into the sea.

Concerning the shape of our AL, experiments of Schumacher and Schmincke [1995] have shown that to produce well-developed spherical aggregates - 30 to $50 \mathrm{vol} \%$ of liquid is required; considering the porosity
(Figure 9) as a proxy for the liquid in our samples, the liquid in the AL ranges from 33 to $40 \mathrm{vol} \%$ for the size interval 4 to $1 \mathrm{~mm}$ and from 20 to 4 vol\% for the size interval 1 to $0.4 \mathrm{~mm}$. The best spherical shape for the $\mathrm{AL}$ is in the size range $2.8 \mathrm{~mm}$ to $1 \mathrm{~mm}$, whereas above 3 and below $1 \mathrm{~mm}$ the AL loses roundness and sphericity. We speculate that, for the largest particles, this is due to deformation and compaction during the fall and landing on the ground. For the smallest particles the decreasing in roundness is a morphological effect as we are actually measuring the roundness of scattered ash pieces held together by few bounding. We discovered that for Punta Lena AL there is a specific aggregates size range ( $2.8 \mathrm{~mm}$ to $1 \mathrm{~mm}$ ) capable of producing well rounded accretionary lapilli; above this size range roundness decreases. Particle shape plays a fundamental role in affecting drag and hence particle trajectory [McNown and Malaika, 1950; Pfeiffer et al., 2005], therefore investigating the evolution of AL shape before and after landing could be useful for constructing better models for deposition of AL either in pyroclastic fall or flow.

\subsection{IMPLICATIONS ON THE DEPOSITIONAL MECHA- NISMS (FALL VS FLOW)}

The SdL sequence has had a number of different interpretations in terms of the origin and emplacement mechanisms. Hornig-Kjarsgaard et al. [1993] and Bertagnini and Landi [1996] interpreted the stratified accretionary lapilli-rich beds as emplaced by prevalent fallout. On contrast, Giordano et al. [2008] and Lucchi et al. [2018] interpreted the basal polydispersed and lithic-bearing layers as the emplacement of the basal higher concentration part of the surge and the accretionary lapilli rich as the dilute co-PDC trail.

The results of this work provided insights on the origin of the AL showing the strong interaction between fragmented ash and seawater. Regarding the depositional mechanisms (fallout vs flow), our results do not allow constraining one emplacement mechanism with respect to another. In support of the fallout interpretation the grain size analysis shows typical Gaussian distribution in $\Phi$ with a Md of $-1.1 \Phi$, testifying an efficient transport and depositional mechanism able to sort the particles similar to a fallout deposit; the data according to Walker [1971] classification method lay into the field of pyroclastic fall and the high presence of AL in the deposits (96\% of aggregates versus $4 \%$ of lose ash material) could also favour the interpretation of deposit as a fallout. From the 3D analysis, following the description 

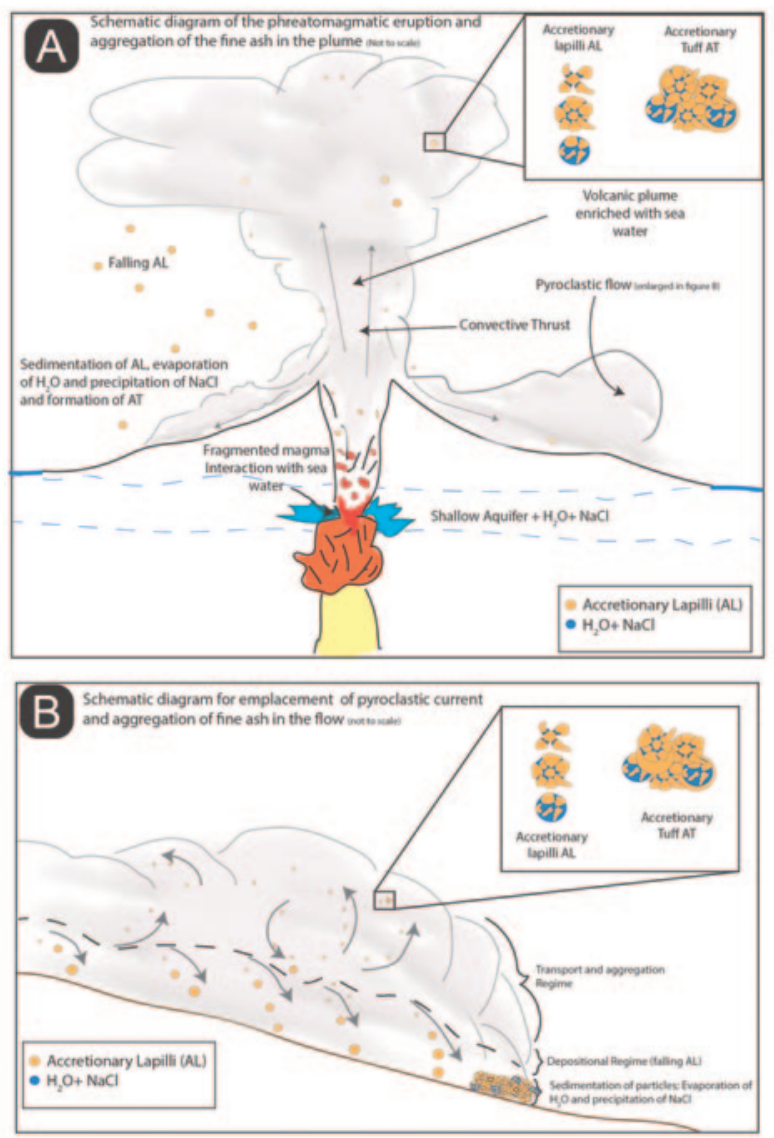

FIGURE 10. Model for emplacement of AL and AT: in the volcanic plume (A) or in the pyroclastic flow (B).

of Brown et al. [2012], we classify our AL as accretionary pellets (AP). In particular, our pellets are mostly poorlystructured pellets AP1 and few AP2 with the latter having a poorly marked rim. According to Brown et al. [2010], AP1 are mostly found as fallout deposits but the same microscopic textures can be also associated with small phreatomagmatic pyroclastic currents, e.g. tuff ring eruptions. In this case, the authors recognize several well-sorted ash aggregates in the basal layers of dilute PDCs at the tuff ring of Tenerife. In the case of SdL eruption, we recognize similar features described by Brown et al. [2010]. We have seen that the SdL, either at Punta Lena or in other out cropping localities, is characterized by continuous alternating of AT and ash $2-15 \mathrm{~cm}$ thick layers. At the SdL type sections, Giordano et al. [2008] recognize that some of these layers pinch out and swell laterally, filling the paleotopography within the lava blocks. Moreover, the authors measured an oriented magnetic lineation for the ash-layers, which are typical of pyroclastic currents where the magnetic grains are oriented parallel to the main flow direction.

Our grain-sized data seem to suggest a fall deposit
(Figure 10A) for SdL, as speculated by Bertagnini and Landi [1996], but the main texture and morphological features of individual ALs can be found associated to a co-ingnimbritic ash plume as well as shown by Brown et al. [2010]. At larger scales, the AT organization may reflect a fall sedimentation process related to a co-ignimbritic ash plumes (Figure 10B).

The SDL phreatomagmatic eruption was triggered during an efficient interaction between the rising magma and seawater, the interaction produced a first phase of small pulsatory and short-lived phreatomagmatic currents when the water supply was prevalent. The AL could had grown within these dilute, turbulent currents and then fallen within the cloud once it reached a certain size. The pulsatory features of this eruption is in accord with the alternation of AL and ash-dominated layers, observed in the outcrop and probably related to variation of seawater availability during the first phases of the eruption (see ash layers alternating with AT layers in the basal unit UA). According to Giordano et al. [2008], we believe that, for each couplet of beds (massive and accretionary lapilli beds), basal massive and lithic-bearing layers are interpreted as the emplacement of the basal high concentration part of the surge, whereas the accretionary lapilli rich is the dilute co-PDC trail. In this sense the accretionary lapilli may fall within a co-PDC cloud. Although unequivocally settle the debate about fall or flow at SdL, which is beyond the scope of this work, we believe that further investigations, such as experiments acted to understand the aggregation of ash particles during the emplacement of dilute pyroclastic currents, are required to better explain the relationship between the AL types and the modalities of their emplacement.

\section{CONCLUSIONS}

In this work we show that seawater played a fundamental role in enhancing aggregation during the eruption of Secche di Lazzaro and that the presence of salt contributes to the stiffening of the particle and to the cementation of the deposit. In SdL samples halite is present at high concentration at different scales (30 to 800 $\mu \mathrm{m})$ between different components (glass, crystals, and lithics) in the AL and between different AL. At Punta Lena most particles in the AT have a diameter equal to $-1 \Phi$, corresponding to $2 \mathrm{~mm}$. AL shows a specific aggregate size range ( $2.8 \mathrm{~mm}$ to $1 \mathrm{~mm}$ ) capable of produc- 
ing well rounded accretionary lapilli; above or below this size range roundness decreases. SdL pellets are mostly poorly-structured pellets (AP1) and few AP2 having a poorly marked rim. The use of X-ray microCT combined with Field Emission - Scanning Electron Microscopy, Electron Microprobe Analysis and X-ray powder diffraction represents a novel approach for the study of ash aggregation and we consider X-ray microCT a pioneering technique and an extraordinary tool for decrypting, in a non-destructive way, the internal texture, and the porosity either of an aggregate or an aggregate tuff.

Acknowledgements. D.M. acknowledges University of Perugia (Progetti Ricerca di Base MORGABASE2015) for funding and Laura Spina and Beatrice Morgavi for support. D.P. acknowledges the European Research Council with the Consolidator grant CHRONOS (612776). A.C. and P.L. acknowledge the European project EUROVOLC (grant agreement number 731070) and the MIUR project Premiale Ash-RESILIENCE. We are gratefully to D. Müller and K. Laeger for support during microprobe analysis. We are also gratefully to Editors D. Mele and F. Dioguardi and two anonymous reviewers for their useful comments and suggestions.

\section{REFERENCES}

Arzilli, F., M. Piochi, A. Mormone, C. Agostini and M.R. Carroll (2016). Constraining pre-eruptive magma conditions and unrest timescales during the Monte Nuovo eruption (1538 ad; Campi Flegrei, Southern Italy): integrating textural and CSD results from experimental and natural trachy-phonolites, Bull. Volcanol., 78, n.72. doi:10.1007/s00445-016-1062-z.

Baker, D.R., F. Brun, C. O’Shaughnessy, L. Mancini, J.L. Fife and M. Rivers (2012a). A four-dimensional Xray tomographic microscopy study of bubble growth in basaltic foam, Nat. Comm., 3, n. 1135. doi: $10.1038 /$ ncomms2134.

Baker, D.R., L. Mancini, M. Polacci, M.D. Higgins, G.A.R. Gualda, R.J. Hill and M.L. Rivers (2012b). An introduction to the application of X-ray microtomography to the three-dimensional study of igneous rocks, Lithos, 148, 262-276. doi: 10.1016/j.lithos.2012.06.008.

Bednarz, U. and H.U. Schmincke (1990). Evolution of the quaternary melilite-nephelinite Herchenberg vol- cano East Eifel, Bull. Volcanol., 52, 426-444.

Bertagnini, A. and P. Landi (1996). The Secche di Lazzaro pyroclastics of Stromboli volcano: a phreatomagmatic eruption related to the Sciara del Fuoco sector collapse, Bull. Volcanol., 58, 239-245.

Bertagnini, A., N. Métrich, L. Francalanci, P. Landi, S. Tommasini and S. Conticelli (2008). Volcanology and magma geochemistry of the present-day activity: constraints on the feeding system. In: Calvari, S., S. Inguaggiato, G. Puglisi, M. Ripepe and M. Rosi (eds) The Stromboli Volcano: An Integrated Study of the 2002-2003 Eruption, AGU, Washington, DC, AGU Geophysical Monograph, Series, 182, 19-37. doi:10.1029/182GM04.

Blunt, M.J., B. Bijeljic, H. Dong, O. Gharbi, S. Iglauer, P. Mostaghimi, A. Paluszny and C. Pentland, (2013). Pore-scale imaging and modeling, Adv. Wat. Res., 51, 197-216.

Bonadonna, C., G.C. Mayberry, E.S. Calder, R.S.J. Sparks, C. Choux, P. Jackson, A.M. Lejeune, S.C. Loughlin, G.E. Norton, W.I. Rose, G. Ryan and S.R. Young (2002). Tephra fallout in the eruption of Soufrière Hills Volcano, Montserrat, Geol. Soc. Mem., 21, 483-516.

Branney, M.J. (1991). Eruption and depositional facies of the Whorney side Tuff Formation, Lake District: an exceptionally large-magnitude phreatoplinian eruption, Geol. Soc. Am. Bull., 103, 886-897.

Brown, R.J, T.L. Barry, M.J. Branney and M.S. Pringle (2003). The Quaternary pyroclastic succession of southeast Tenerife, Canary Islands: explosive eruptions, related caldera subsidence, and sector collapse, Geol. Mag., 140, 265-288.

Brown, R.J., M.J. Branney, C. Maher and P. Dávila-Harris (2010). Origin of accretionary lapilli with ground-hugging density currents: evidence from pyroclastic couplets on Tenerife, Bull. Geol. Soc. Am., 122, 305-320.

Brown, R.J, C. Bonadonna, and A.J. Durant (2012). A review of volcanic ash aggregation, Physics and Chemistry of the Earth, 45-46, 65-78.

Calvari, S., L. Spampinato, L. Lodato, A.J.L. Harris, M.R. Patrick, J. Dehn, M.R. Burton and D. Andronico (2005). Chronology and complex volcanic processes during the 2002--2003 flank eruption at Stromboli volcano (Italy) reconstructed from direct observations and surveys with a handheld thermal camera, J. Geophys. Res., 110, B02201. doi:10.1029/2004JB003129. 
Carey, S.N. and H. Sigurdsson (1982). Influence of particle aggregation on deposition of distal tephra from the May 181980 eruption of Mount St. Helens volcano, J. Geophys. Res., 87, 7061-7072.

Carey, S., H. Sigurdsson, C. Mandeville and S. Bronto (1996). Pyroclastic flows and surges over water: an example from the 1883 Krakatau eruption, Bull. Volcanol., 57, 493-511.

Carlson, W.D. (2006). Three-dimensional imaging of earth and planetary materials, Earth Planet. Sci. Lett., 249, 133-147.

Cole, D. and C. Scarpati (1993). A facies interpretation of the eruption and emplacement mechanisms of the upper part of the Neapolitan Yellow Tuff, Campi Flegrei, southern Italy, Bull. Volcanol., 55, 311-326.

Costa, A., A. Folch and G. Macedonio (2010). A model for wet aggregation of ash particles in volcanic plumes and clouds: 1. Theoretical formulation, J. Geophys. Res., 115, B09201. doi:10.1029/2009JB007175.

De Astis, G., C.A. Tranne, F. Lucchi, (2006) The Aeolian volcanic district: volcanism and magmatism. Acta vulcanologica, Vol. 18

Del Bello, E., J. Taddeucci, P. Scarlato, E. Giacalone and C. Cesaroni (2015). Experimental investigation of the aggregation-disaggregation of colliding volcanic ash particles in turbulent, low-humidity suspensions, Geophys. Res. Lett., 42, 1068-1075. doi:10.1002/2014GL062292.

Dollase, W.A. (1986). Correction of intensities for preferred orientation in powder diffractometry: application of the March model, J. Appl. Cryst., 19, 267-272.

Dufek, J. Manga M. and Staedter M. (2007). Littoral blast: Pumice-water heat transfer and theconditions for steam explosions when pyroclastic flows enter the ocean Journal of Geophysical Research vol. 112 B11201

Durant, A.J. and W.I. Rose (2009). Sedimentological constraints on hydrometeor-enhanced particle deposition: 1992 eruptions of Crater Peak, Alaska, J. Volcanol. Geotherm. Res., 186, 40-59.

Edgar, C.J., J.A. Wolff, P.H. Olin, H.J. Nichols, A. Pittari, R.A.F. Cas., P.W. Reiners, T. L. Spell and J. Marti (2007). The late quaternary Diego Hernandez Formation, Tenerife: volcanology of a complex cycle of voluminous explosive phonolitic eruptions, J. Volcanol. Geotherm. Res., 160, 59-85.
Feldkamp, L.A., L.C. Davis and J.W. Kress (1984). Practical cone-beam algorithm, J. Opt. Soc. of America, 1, 612-619.

Fisher, R.V. (1961). Proposed classification of volcaniclastic sediments and rocks, Bull. Geol. Soc. Am., 72, 1409-1414.

Fisher, R.V. and H.U. Schmincke (1984). Pyroclastic Fragments and Deposits, Pyroclastic Rocks, 89124.

Francalanci, L., F. Lucchi, J. Keller, G. De Astis and C.A. Tranne (2013). Eruptive, volcano-tectonic and magmatic history of the Stromboli volcano (northeastern Aeolian archipelago), Geol. Soc. London, Memoirs 2013, 37, 397-471. doi: 10.1144/M37.13.

Fusseis, F., X. Xiao, C. Schrank and F. De Carlo (2014). A brief guide to synchrotron radiation-based microtomography in (structural) geology and rock mechanics, J. Struct. Geol., 65, 1-16.

Gilbert, J.S. and S.J. Lane (1994). The origin of accretionary lapilli, Bull. Volcanol., 56, 398-411.

Giordano, G., M. Porreca, P. Musacchio, and M. Mattei (2008). The Holocene Secche di Lazzaro phreatomagmatic succession (Stromboli, Italy): evidence of pyroclastic density current origin deduced by facies analysis and AMS flow directions, Bull. Volcanol., 70, 1221-1236.

Gualda, G.A.R., A.S. Pamukcu, L.L. Claiborne and M.L. Rivers (2010). Quantitative 3D petrogra- phy using X-ray tomography 3: documenting accessory phases with differential absorption tomography, Geosphere, 6, 782-792.

Hayakawa, Y. (1990). Mode of eruption and deposition of the Hachinohe phreatoplinian ash from the Towada Volcano, Japan, Geograph. Rep. Tokyo Met. Univ., 25, 167-182.

Hildreth, W. and R.E. Drake (1992). Volcan Quizapu, Chilean Andes, Bull. Volcanol., 54, 93-125.

Hill, R.J. and C.J. Howard (1987). Quantitative phase analysis from neutron powder diffraction data using the Rietveld method, J. Appl. Cryst., 20, 467474.

Hornig-Kjarsgaard, I., J. Keller, U. Koberski, E. Stadlbauer, L. Francalanci and R. Lenhart (1993). Geology, stratigraphy and volcanological evolution of the island of Stromboli, Aeolian arc, Italy. Acta Vulcanol, 3, 21-68.

Iglauer, S., M.A. Fernø, P. Shearing and M.J. Blunt (2012). Comparison of residual oil cluster size distribution, morphology and saturation in oil-wet 
and water-wet sandstone, J. Coll. Interf. Sci., 375, 187-192.

Inman, D.L. (1952). Measures for describing the size distribution of sediments, J. Sedim. Res., 22, 125-145. doi.org/10.1306/D 42694D B - 2B 26 - 11D 7 8648000102C1865D.

Junqueira-Brod, T.C., J.C. Gaspar, J.A. Brod and C.V. Kafino (2005). Kamafugitic diatremes: their textures and field relationships with examples from the Goia's alkaline province, Brazil, J. South Am. Earth. Sci., 18, 337-353.

Ketcham, R.A. and W.D. Carlson (2001). Acquisition, optimization and interpretation of X-ray computed tomographic imagery: applications to the geosciences, Comp. \&t Geosci., 27, 381-400.

Ketcham, R.A. (2005). Computational methods for quantitative analysis of three- dimensional features in geological specimens, Geosphere, 1, 32-41.

Lane, S.J., J.S. Gilbert and M. Hilton (1993). The aerodynamic behaviour of volcanic aggregates, Bull. Volcanol., 55, 481-488.

Larson, A. C. and R.B. von Dreele (2004). General Structure Analysis System (GSAS). Report LAUR 86748, Los Alamos National Laboratory, New Mexico, USA.

Le Bas, M. J., R.W. Le Maitre, A. Streckeisen and B. Zanettin (1986). A chemical classification of volcanic rocks on the total alkali 2 silica diagram, J. Petrol., 27, 745-750.

Lucchi F., L. Francalanci, G. De Astis, et al. (2018). Geological evidence for recurrent collapse-driven phreatomagmatic pyroclastic density currents in the Holocene activity of Stromboli volcano, Italy. J Volcanol Geotherm Res. doi: 10.1016/j.jvolgeores.2018.10.024.

McNown J.S. and J. Malaika J. (1950). Effects of particle shape on settling velocity at low Reynolds numbers. Transactions. American Geophysical Union Vol. 31, N. 1.

Mees, F., R. Swenner, M. Van Geet and P. Jacobs (2003). Application of X-ray computed tomography in the Geosciences. In: Mees, F., R. Swenner, M., Van Geet and P. Jacobs (Eds.), Application of X-ray Computed Tomography in the Geosciences: Geol. Soc. London, Spec. Publ. 215, 1-6.

Morgavi, D., F. Arzilli, C. Pritchard, D. Perugini, L. Mancini, P. Larson and D.B. Dingwell (2016). The Grizzly Lake complex (Yellowstone Volcano, USA): Mixing between basalt and rhyolite unraveled by microanalysis and X-ray microtomography, Lithos 260, 457-474. doi.org/10.1016/j.lithos.2016.03.026.

Mueller, S.B., U. Kueppers, P.M. Ayris, M. Jacob and D.B. Dingwell (2016). Experimental volcanic ash aggregation: Internal structuring of accretionary lapilli and the role of liquid bonding, Earth Planet. Sci. Lett., 433, 232-240. doi.org/10.1016/j.epsl.2015.11.007.

Mueller, S.B., P.M. Ayris, F.B. Wadsworth, U. Kueppers, A.S. Casas, P. Delmelle, J. Taddeucci, M. Jacob and D.B. Dingwell (2017). Ash aggregation enhanced by deposition and redistribution of salt on the surface of volcanic ash in eruption plumes, Sci. Rep., 7, n. 45762. doi: 10.1038/srep45762.

Mueller, S.B., Kueppers, U., Huber, M.S., Kai-Uwe Hess K., Poesges G., Ruthensteineret B., D.B. Dingwell (2018) Aggregation in particle rich environments: a textural study of examples from volcanic eruptions, meteorite impacts, and fluidized bed processing. Bull Volcanol 80: 32. https://doi.org/10.1007/s00445-018-1207-3

Palladino, D.M., M. Gaeta and F. Marra (2001). A large $\mathrm{K}$-foiditic hydromagmatic eruption from the early activity of the Alban Hills Volcanic District, Italy, Bull. Volcanol., 63, 345-359.

Paredes-Mariño, J., D. Morgavi, M. Di Vito, S. de Vita, F. Sansivero, K. Dueffels, G. Beckmann and D. Perugini (2017). Syneruptive sequential fragmentation of pyroclasts from fractal modeling of grain size distributions of fall deposits: the Cretaio Tephra eruption (Ischia Island, Italy), J. Volcanol. Geotherm. Res., 345, 161-171. doi.org/10.1016/j.jvolgeores.2017.07.020.

Petrone, C. M., E. Braschi and L. Francalanci (2009). Understanding the collapse-eruption link at Stromboli, Italy: a microanalytical study on the products of the recent Secche di Lazzaro phreatomagmatic activity, J. Volcanol. Geotherm. Res., 34, 153-172.

Pfeiffer, T., A. Costa A., G. Macedonio (2005). A model for the numerical simulation of tephra fall deposits, J. Volcanol. Geotherm. Res., 140, 273-294, doi:10.1016/j.jvolgeores.2004.09.001.

Polacci, M., L. Mancini and D.R. baker (2010). The contribution of synchrotron X-ray computed microtomography to understanding volcanic processes, J. Sinchrot. Rad., 17, 215-221. doi: 10.1107/S0909049509048225.

Porreca, M., G. Giordano, M. Mattei and P. Musacchio (2006). Evidence of two Holocene phreatomag- 
matic eruptions at Stromboli volcano (Aeolian Islands) from paleomagnetic data, Geophys. Res. Lett., 33, L21316. doi:10.1029/2006GL027575.

Pouchou, L. and F. Pichoir (1984). A new model for quantitative X-ray microanalysis. Part I: Application to the analysis of homogeneous samples, Rec. Aerosp., 3, 13-38.

Ridler, T.W. and S. Calvard (1978). Picture thresholding using an iterative selection method, IEEE Trans. Syst. Man Cybern., 8, 630-632. doi:10.1109/TSMC.1978.4310039.

Rietveld, H. M. (1969). A profile refinement method for nuclear and magnetic structures, J. Appl. Cryst., 2, 65-71.

Rose, W. and J. Durant (2009). Fine ash content of explosive eruptions, J. Volcanol. Geotherm. Res., 186, 32-39.

Rosi, M. (1980). The Island of Stromboli, Rend. Soc. It. Miner. Petrol., 36, 1-24.

Rosi, M. (1992). A model for the formation of vesiculated tuff by the coalescence of accretionary lapilli, Bull. Volcanol., 54, 429-434.

Rosi, M., A. Bertagnini and P. Landi (2000). Onset of the persistent activity at Stromboli volcano (Italy), Bull. Volcanol., 62, 294-300.

Schmid, R. (1981). Descriptive nomenclature and classification of pyroclastic rocks and fragments: recommendations of the IUGS Sub commission on the systematics of Igneous Rocks, Geology, 9, 41-43.

Schneider, C.A., S.R. Wayne and K.W. Eliceiri (2012). NIH Image to Image $\mathrm{J} 25$ years of image analysis, Nat. Meth., 9, 671-675.

Schumacher, R. and H.U. Schmincke (1991). Internal structure and occurrence of accretionary lapilli - a case study at Laacher See volcano, Bull Volcanol., 53, 612-634.

Schumacher, R. and H.U. Schmincke (1995). Models for the origin of accretionary lapilli, Bull. Volcanol., $56,626-639$.

Segre, A. (1968). Notizie sulla morfologia submarina di Stromboli, Riv. Stromboli, 11, 45-50.

Sisson, T.W. (1995). Blast ashfall deposit of May, 18, 1980 at Mount St. Helens Washington, J. Volcanol. Geotherm. Res., 66, 203-216.

Sorem, R.K. (1982). Volcanic ash clusters: tephra rafts and scavengers, J. Volcanol. Geotherm. Res., 13, 63-71.

Sparks, R.S.J., M. I. Bursik, S. Carey, J.S. Gilbert, L.S. Glaze, H. Sigurdsson and A.W. Woods (1997), Vol- canic Plumes, John Wiley, New York.

Speranza, F., M. Pompilio, F. D’Ajello Caracciolo and L. Sagnotti (2008). Holocene eruptive history of the Stromboli volcano: constraints from paleomagnetic dating. Journal of Geophysical Research, 113, B09101.

Thompson, P., D.E. Cox and J.B. Hastings (1987). Rietveld refinement of Debye-Scherrer synchrotron X-ray data from Al203, J. Appl. Cryst., 20, 79-83.

Tinti, S., A. Maramai and L. Graziani (2004). The New Catalogue of Italian Tsunamis, Nat. Hazards, 33, 439-465.

Tommasi, P., P. Baldi, F.L. Chiocci, M. Coltelli, M. Marsella, M. Pompilio and C. Romagnoli (2005). The landslide sequence induced by the 2002 eruption at Stromboli Volcano, in: Sassa K., H. Fukuoka, F. Wang and G. Wang (eds), Landslides, Springer, Berlin, Heidelberg. doi.org/10.1007/3540-28680-2_32.

Trusdell, F.A., R.B. Moore, M. Sako, R.A. White, S.K. Koyanagi, R. Chong and J.T. Camacho (2005). The 2003 eruption of Anatahan volcano, Commonwealth of the Northern Mariana Islands: chronology, volcanology, and deformation, J. Volcanol. Geotherm. Res., 146, 184-207.

Valentini, L., B. Marchesini, M. Parisatto, D. Perugini and G. Artioli (2015). Non-invasive assessment of the formation of tourmaline nodules by X-ray microtomography and computer modeling, Am. Mineral., 100, 459-465.

Van Eaton, A.R., J. Muirhead, C.J.N. Wilson and C. Cimarelli (2012). Growth of volcanic ash aggregates in the presence of liquid water and ice: an experimental approach, Bull. Volcanol., 74, 19631984. doi: 10.1007/s00445-012-0634-9.

Voltolini, M., D. Zandomeneghi, L. Mancini and M. Polacci (2011). Texture analysis of volcanic rock samples: quantitative study of crystals and bubbles shape preferred orientation from X-ray microtomography data, J. Volcanol. Geotherm. Res., 202, 83-95.

Walker, G.P.L. (1971). Grain-size characteristics of pyroclastic deposits, J. Geol., 79, 696-714.

Walker, G.P.L. (1973). Explosive Volcanic Eruptions - A New Classification Scheme. Geologische Rundschau, 62, 431-446.

Walker, G.P.L. (1981). Plinian eruptions and their products, Bull. Volcanol. 44, 223-240. doi: 10.1007/BF02600561. 
Watanabe, K., K. Ono, K. Sakaguchi, A. Takada and H. Hoshizumi (1999). Co-pyroclastic density current ash-fall deposits of the 1991 eruptions of Fugendake, Unzen Volcano, Japan, J. Volcanol. Geotherm. Res., 89, 95-112.

Wiesmaier, S., D. Morgavi, C.J., Renggli, D. Perugini, C.P. De Campos, K.U. Hess, W. Ertel-Ingrisch, Y. Lavallée and D.B. Dingwell (2015). Magma mixing enhanced by bubble segregation, Solid Earth, 6, 1007-1023.

*CORRESPONDING AUTHOR: Daniele MORGAVI, Department of Physics and Geology, University of Perugia Perugia, Italy email: daniele.morgavi@unipg.it 